\title{
THE IMMUNOLOGY OF ULCERATIVE COLITIS AND CROHN'S DISEASE
}

\author{
Dr D P JEWELL, MA, DPhil, FRCP \\ The Royal Free Hospital, London
}

The aetiology of ulcerative colitis and Crohn's disease remains unknown but many immunological phenomena have been reported. This lecture will briefly categorize these and will, inevitably, not go into any of the detailed controversy that exists.

\section{Humoral immune responses}

The basic humoral immune responses of these patients appears to be normal. For ulcerative colitis, serum immunoglobulin levels are essentially normal. They may be mildly elevated in patients with active disease but fall to within a normal range when the disease goes into remission (Hodgson and Jewell'). There has been some recent evidence suggesting that some patients with ulcerative colitis have hyposplenism (Ryan $\mathrm{el} a l^{2}$ ) and our own data suggests that these are patients who have had the disease for many years (Figure 1). This may obviously influence antibody production and, indeed, there are impaired primary and secondary responses to the bacteniophiage $\emptyset \times 174$. However, as will be mentioned later, these patientis often have elevated antibody titres to dietary and bacterial antigens and there is increased synthesis of IgG. It seems unlikely therefore, that there is a generalised impairment of antibody production.

For Crohn's disease, immunoglobulin levels are also essentially normal but in acute Crohn's disease there if often an elevation of serum IgA and IgM. Following colectomy for Crohn's disease, the IgM rises (Gelernt et $a l^{3}$, Hodgson and Jewell') but the reasons for this are not clear. Hyposplenism is probably less commonly seen than in ulcerative colitis and there is no relation to the length of history (Figure 1). IgG synthesis is often elevated in Crohn's patients and they usually have raised antibody titres to dietary and bacterial antigens.

Serum complement levels are helpful in assessing the activity of either disease but many of the individual components act as acute phase reactants. Hence, raised levels of $\mathrm{C} 3$ and Factor B are usually associated with active disease but fall to normal during remission (Feinstein $e l a^{4}$, Hodgson et al ${ }^{5}$ ). Nevertheless, metabolic turnover studies have shown that there is increased catabolism and synthesis of $\mathrm{Clq}$ and $\mathrm{C} 3$ in both ulcerative colitis and Crohn's disease (Hodgson et al ${ }^{8}$, Potter $\left.e t a l^{7}\right)$. Figure 2 shows an example. Purified Clq, labelled with ${ }^{125} \mathrm{I}$ was injected into patients with ulcerative colitis. It will be seen that the radioactive protein disappears from plasma more rapidly than in the normal controls. When faecal and urine losses are taken into account, the synthesis and catabolic rates can be calculated and shown to be increased. The increased metabolism of complement components, especially $\mathrm{C} 1$ and $\mathrm{C} 3$, is strong evidence that antigen-antibody reactions are taking place in those patients. 


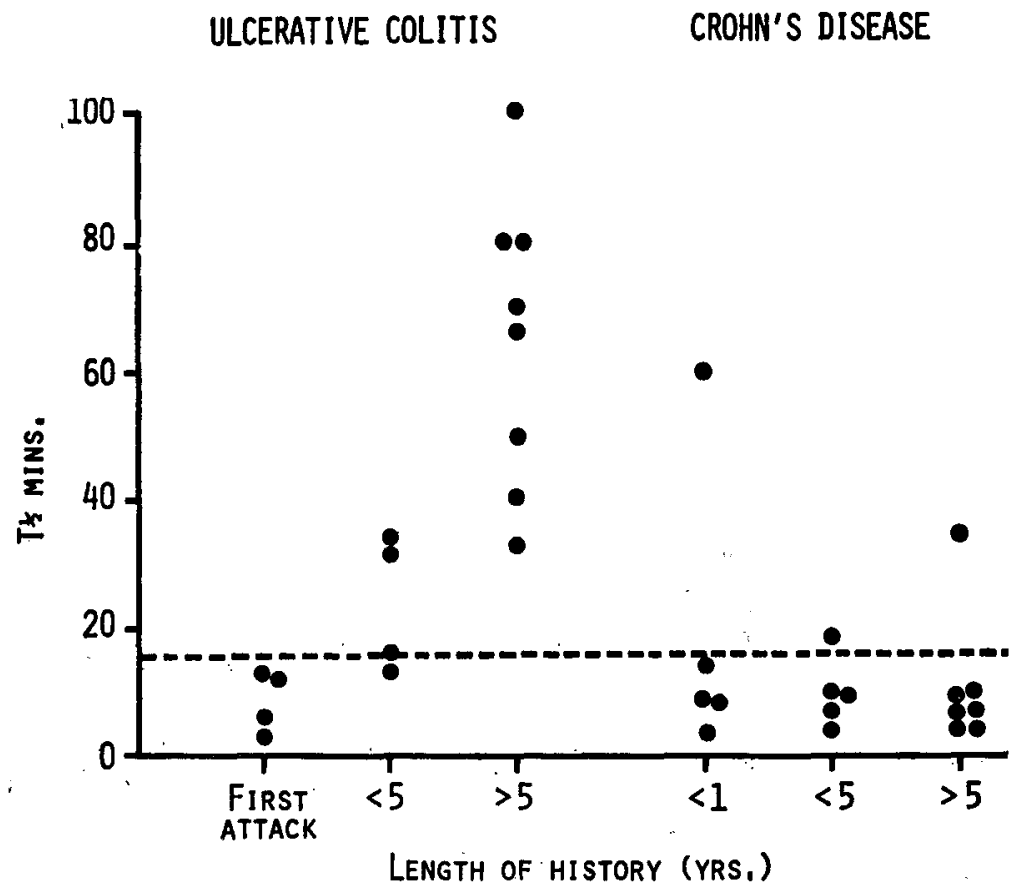

Fig 1. Splenic function in patients with ulcerative colitis and Crohn's disease. Half-clearance time of 51 Cr-labelled heat damaged cells related to length of history. Dotted line-upper limit of normal.

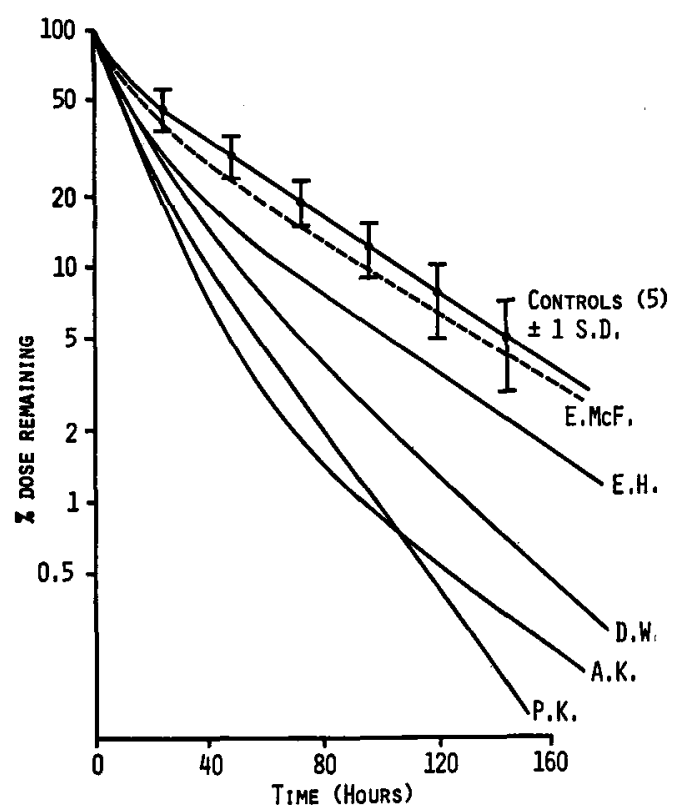

Fig 2. Plasma disappearance curves of 125 I- labelled Clq in patients with ulcerative colitis and normal control subjects. E. McF, was in remission; the other patients had active disease. 
Cell mediated immunity

The $\mathrm{T}$ and $\mathrm{B}$ cell populations in the peripheral blood of patients with ulcerative colitis are normal. Similarly skin testing for delayed hypersensitivity to antigens such as purified protein derivative (tuberoulin), mumps, candida and dinitrochlorobenzene is normal and there is a normal response of patient's lymphocytes to non-specific mitogens, such as phytohaemagglutinin. There is, therefore, no impairment of the cellular immune syitem in ulcerative colitis. The role of the $\mathrm{K}$ cell is unclear at the moment as some authors find $\mathrm{K}$ cell activity to be increased while others find it diminished.

For patients with Crohn's disease the situation is confused. There are many reports of a diminished population of circulating $\mathrm{T}$ cells, an impaired delayed hypersensitivity on skin testing and a reduced response to non-specific mitogens. However, many investigators have been unable to show any differences from control subjects, especially when compared with patients with malabsorption secondary to gastric surgery (reviewed by Jewell and Hodgson ${ }^{8}$ ). If cell-mediated immunity is impaired in patients with Crohn's disease, a number of reasons can be put forward to explain the phenomenon. Firstly, there may be a depression of $\mathrm{T}$ cells as a result of nutritional deficiencies. Secondly, $\mathrm{T}$ cells may be lost from the inflamed intestine, and thirdly, the $\mathrm{T}$ cells may specifically home into the affected bowel. Any or all of these mechanisms may be operative and could lead to a reduction in the circulating pool of $T$ cells resulting in impaired responses to skin testing and ito non-specific mitogens.

Recently it has been reported that neutrophils from patients with Crohn's disease do not migrate normally, as assessed by a skin window technique, although they show normal in vitro chemotaxis $\left(\mathrm{Segal}^{9}\right)$. Neutrophils in patients with ulcerative colitis showed normal migration, as did monocytes in both diseases. Dr Mee, working in my laboratory has confirmed earlier reponts of an absolute monocytosis in the peripheral blood of patients with both ulcerative colitis and Crohn's disease. In addition, he has shown that the monocytes exhibit increased phagocytosis and that they contain increased lysosomal enzyme activity.

It seems likely that these findings indicate activated monocytes, i.e. monocytes which are transforming inito macrophages. The factors which are responsible for 'turning on' monocytes are unknown but endotoxin, activated complement components and immune complexes are possible candidates. So far, no differences have been found between ulcerative colitis and Crohn's disease. This is perhaps surprising since macrophages, which are derived from circulating monocytes are more predominant in Crohn's inflammation than in ulcerative colitis.

\section{Immune responses to exogenous antigens}

Ulcerative colitis was regarded as a manifestation of a food allergy for many years and milk appeared to be the major allergen. However, although patients may show higher titres of circulating antibodies to the milk proteins and to egg albumin when compared with healthy individuals, there is no evidence to support food allergy as the cause of the disease or, indeed, of Crohn's disease. It is likely that the intestinal inflammation allows increased absorption of dietary protein with subsequent elevation of antibody titres. 
Patients with ulcerative colitis and Crohn's disease frequently show elevated antibody titres to colonic bacteria and some of this antibody is produced by plasma cells within the inflamed lamina propria (Thayer et $a l^{10}$, Monteiro et al ${ }^{14}$. Tabaqchali et $\left.a l^{12}\right)$. Cellular hypersensitivity to a variety of strains of $E$ coli has also been demonstrated in these patients using lymphocyte transformation and leucocyte migration inhibition techniques. The significance of these immune responses to bacterial antigens is not known. They almost certainly arise as a secondary phenomenon as a result of increased absorption of antigen through the inflamed mucosa. However, they may influence the inflammatory response in the lamina propria as will be discussed later.

\section{Immune responses to auto-antigens}

Patients with either ulcerative colitis or Crohn's disease do not have an increase in auto-antibodies such as anti-nuclear antibody, parietal cell canalicular antibody, smooth muscle and thyroid antibodies. However, they may possess antibodies to colonic epithelium although they are only found in about 30 per cent of sera from patients with ulcerative colitis and even less frequently in Crohn's disease (Wright and Truelove ${ }^{13}$ ). The height of the titre cannot be correllated with any of the clinical features of the diseases such as extent, severity, or length of history. The antigen to which these antibodies are directed is located in the goblet cells and appears to be a lipopolysaccharide. (Lagercrantz et $a l^{14}$ ) have shown that it cross relacts with an antigen in E. coli. It is therefore possible that these auto-antibodies to colon may arise secondarily to the immune response directed towards the colonic flora. Cell-mediated responses to colonic antigens have also been shown in these patients but whether the antigen eliciting the cellular response is the same as the goblet cell antigen which crossreacts with baterial antigen is not known.

\section{Lymphocytotoxic antibodies}

Recently, lymphocytotioxic antibodies have been described in patients with inflammatory bowel disease (Korsmeyer et $a^{15}$ ). Since, a high proportion of household contacts also possessed lymphocytotoxic antlibodies in their sera, it has been suggested that these findings might support an infective aetiology for inflammatory bowel disease. However, similar antibodies have also been found in patients with other diseases such as systemic lupus erythematosus and rheumatoid arthritis and also in their contacts, so they are not specific for inflammatory bowel disease.

\section{Lymphocyte cytotoxicity}

Lymphocytes from patienits with both Crohn's disease and ulcerative colitis are able to kill colonic epithelial cells in vitro. All patients' lymphocytes behave in this way, whereas the property is not shared by lymphocytes from healthy controls. In some patients, lymphocyte cytotoxicity is lost following colectomy. Table I summarizes the details of this cytotoxic reaction. The exact immunological mechanisms involved are not understood and the matter is complicated by further studies showing that this form of cytotoxicity can be induced in normal lymphocytes by incubating them with $\mathrm{E}$. coli and with serum from patients with inflam- 
Table I

Lymphocyte cytotoxicity to colonic epithelial cells

\begin{tabular}{|c|c|c|c|}
\hline 1 & Specific for colonic cells & \multirow[t]{2}{*}{4} & \multirow{2}{*}{$\begin{array}{l}\text { Persists during remission, but } \\
\text { may disappear following } \\
\text { colectomy }\end{array}$} \\
\hline 2 & Not dependent on complement & & \\
\hline 3 & $\begin{array}{l}\text { Present in all patients with } \\
\text { inflammatory bowel disease }\end{array}$ & $J$ & from other patients with IBD, \\
\hline
\end{tabular}

matory bowel disease. Lymphocyte killing of target cells is an important effector mechanism mediating immunological damage but evidence for an in vivo role of these in vitro phenomena is lacking.

\section{Immune complexes}

Recently there has been much discussion on the role of immune complexes in the pathogenesis of inflammatory bowel disease. Table II lists the methods that

Table II

Methods used to demonstrate circulating immune complexes in patients with inflammatory bowl disease

\begin{tabular}{|c|c|}
\hline Anti-complementary activity & Inhibition of $\mathrm{K}$ cell cytotoxicity \\
\hline C1q precipitation in gel & $\begin{array}{c}\text { Inhibition of agglutination of Ig-coated } \\
\text { particles. }\end{array}$ \\
\hline 125 I-Clq precipitation with PEG & $\begin{array}{c}\text { Inhibition of complement-dependent } \\
\text { lymphocyte rosetting }\end{array}$ \\
\hline
\end{tabular}

have been used to demonstrate soluble complexes in the circulation of these patients. Unfortunately, none of them are entirely satisfactory, but that applies to all tests for immune complexes where the antigen is not known. However, most of the tests have shown rather similar results which lends support to the hypothesis that complexes exist in the sera. They are most frequently found in the sera of patients with active disease and, for patients with Crohn's disease, they are particularly related to colonic involvement. High titres of complexes are found in patients who have certain of the extra-intestinal manifestations-acute arthritis, uveitis and erythema nodosum. It has been suggested, therefore, that these manifestations may be caused by the deposition of complexes in the peripheral tissues (Hodgson $e t a^{16}$ ). This would certainly explain the clinical association between these extra-intestinal features and Crohn's colitis in contrast to their infrequency in ileal Crohn's disease where circulating complexes are also infrequent.

The origins of the circulating complexes is presumed to be the inflamed intestine although there is no evidence to support this. It is however a reasonable hypothesis to suggest that immune complexes are formed within the lamina propria. There is a marked increase in IgG-producing plasma cells in both Crohn's disease and ulcerative colitis (Baklien and Brandtzaeg ${ }^{17}$ ) and some of this immunoglobulin has antibody specificity for bacterial antigens (Monteiro $e t a^{11}$ ). 
Immune complexes mediate tissue damage in a number of ways. Large complexes fix complement and this will result in the release of opsonizing factors, vasoactive amines and chemotactant factors. That complement metabolism is increased has already been discussed and is supported by the demonstration of complement degradation products and antibodies to activated complement components in serum. In addition to complement activation, immune complexes release tissue damaging enzymes from the lysosomes of monocyites, they activate the clotting sequence and increase phagocytosis by neutrophils and monocytes. The final result of these mechanisms is the classical Arthus reaction. The histological lesion of ulcerative colitis has many features in common with an Arthus reaction:- vascular dilatation, oedema, and a cellular infiltration with neutrophils, plasma cells and eosinophils. Crohn's disease, however, does not share these features in its most typical form and more closely resembles a cell-mediated reaction - the cellular infiltrate consists of lymphocytes and macrophages, and granulomata occur in about 70 per cent of patients.

Nevertheless, the immune phenomena described for both diseases are very similar and no clear difference has been found to account for the differing histological appearances. If immune complexes are involved in the pathogenesis of the mucosal inflammation, it is possible that the similarities and the differences between the two diseases may depend in part on the size of the immune complex involved. This, in turn, would depend on the size and concentration of the antigen or antigens. There is some experimental evidence to support this hypothesis. Immune complexes made at equivalence caused granuloma when injected intradermally in rats whereas soluble complexes made in antibody excess caused a typical Arthus reaction (Spector and $\mathrm{Heesom}^{18}$ ). At the moment this must remain an interesting speculation in relation to inflammatory bowel disease but it would certainly explain many of the clinical features of the two diseases.

\section{Experimental colitis}

An animal model of colitis based on immune complexes has recently been developed (Hodgson et $a l^{19}$ ). This model differs from previous attempts to induce colitis in animals in so far as the immunological effector mechanisms involved were carefully controlled by using pre-formed complexes and the histological lesions produced were remarkably similar to human ulcerative colitis. A very mild hyperaemia of the rectum was first induced in rabbits by the instillation of a dilute formalin solution. Then pre-formed immune complexes were injected intravenously. According to the Auer Principle, circulating complexes deposit preferentially in sites of previous inflammation. Serial rectal biopsies were therefore performed following the injection of complexes. All animals injected with complexes developed sigmoidoscopic and histological evidence of an acute colitis within 24 hours and it was maximal at the end of the first week. Biopsies at this stage showed vascular dilatation, an acute inflammatory infiltrate with the formation of crypt abscesses, and ulceration of the surface epithelium.

However, this procedure only resulted in an acute colitis and by three months the rabbits' mucosae returned to normal. The experiment was therefore repeated using rabbits which had previously been immunised with the Kunin antigen-an 
antigen common to all Enterobacteria (Mee $e t a l^{20}$ ). It was argued that if an acute colitis developed in an animal sensitised to antigens within the colon, then absorption of these antigens might cause further immunological damage and eventually cause a chronic colitis. Animals sensitised to the Kunin antigen who received intra rectal formalin and intravenous human serum albumin (HSA) or anti-HSA developed minimal and transient changes in the rectum. However, the sensitised animals which were given HSA- anti-HSA complexes developed an acute colitis, as expected, but the inflammatory infiltrate persisted. At six months these animals still showed the appearances of an acute-on chronic colitis-an acute inflammatory infiltrate with gland atrophy and distorted glands.

The results obtained from these animals allow a number of statements to be made. Firstly, immune complex damage in the colon induces a histological lesion which is very similar to human ulcerative colitis. Secondly, such a lesion occurring in an animal sensitised to colonic antigens may develop into a chronic colitis. The implications for the pathogenesis of ulcerative colitis are clear but, so far, direct evidence is lacking.

\section{REFERENCES}

1. Hodgson, H J F AND Jewell D P (1978). American Journal of Digestive Diseases 23, 123-128.

2. RYAN, F P, et al (1978). Gut 19, 50-55.

3. Gelernt, I M, Present, D H and Janowitz, H D (1972). Gut 13, 21-23.

4. Feinstein, P A, Kaplan, S R and Theyer, W R (1976).Gastroenterology 70, 181-185.

5. Hodgson, H J F, Potter B J and Jewell, D P (1977). Gut 18, 749-753.

6. Hodgson, H J F, Potter, B J ANd Jewell (1977). Clinical and Experimental Immunology. 28, 490.

7. Potter, B J et al (1979). Gut (Impress).

8. Jewell, D P AND Hodgson, H J F (1976). Auto-immune and inflammatory diseases of the gastro-intestinal tract. In Immunological Aspects of the Liver and Gastro-intestinal Tract. Ed A Ferguson and R N M MacSween. M. T. P. Press Ltd., Lancaster.

9. Segal, A W And Loewi, G (1976). Lancet ii, 219-221.

10. THAYER, W R et al (1969). Gastroenterology 57, 311-318.

11. Monteiro, E et al (1971). Lancet i, 249.

12. Tabaqchali, S, O'Donogue, D P and Bettelheim, K A (1978). Gut 19, 108-113.

13. Wright, R and Truelove, S C (1966). Gut 7, 32-40.

14. Lagercrantz, $\mathrm{R}$ et al (1969) Journal of Experimental Medicine 128, 1339-1382.

15. KORSMEYER, S et al (1974), Gastroenterology 67, 578-583.

16 Hodgson, H J F, Potter, B J AND Jewell, D P (1977). Clinical and Experimental Immunology 29, 187-196.

17. Baklein, K and Brandtzaeg, P (1975). Clinical and Experimental Immunology 22, 197209.

18. Spector, W G and Heesom, N (1969). Journal of Pathology 98, 31.

19. Hodgson, H J F et al (1978). Gut 19, 225-232.

20. MEE, A S et al (1978). Gut. 20, 1. 